\title{
Knowledge, attitudes, and behaviors of parents towards varicella and its vaccination
}

\author{
Luigi Vezzosi, Gabriella Santagati and Italo F. Angelillo*
}

\begin{abstract}
Background: The aims of this cross-sectional survey were to examine the knowledge, the attitudes, and the behavior regarding the varicella infection and its vaccination and to get insight into their determinants among parents of children in Italy.

Methods: From May to June 2015 in the geographic area of Naples (Italy) a random sample of 675 parents of children aged 4-7 years received a self-administered anonymous questionnaire about socio-demographic characteristics, knowledge, attitudes, and behaviors towards varicella and its vaccination.

Results: A total of 414 parents responded to the questionnaire, for a response rate of $61.3 \%$. A history of varicella was reported in 163 children (39.6\%). Only 26.6\% parents knew that the vaccine was available and the number of doses and this knowledge was significantly higher in those who had a university degree, in those who had received information on the vaccination from a health care provider, and in those who had vaccinated their child. The perceived utility towards vaccination had a mean value of 5.7. The positive attitude towards the utility of the vaccination was higher in parents with a level of education not higher than middle school, in those who had vaccinated their child, in those who considered the varicella a dangerous disease, and in those who had received information from a health care provider. More than one-third had vaccinated their child. Immunization was more frequent in parents who had knowledge about the vaccination, who beliefs that the immunization was useful, who believed that the disease was not dangerous, and who had not a history of varicella among their children.
\end{abstract}

Conclusions: Educational programs are needed among parents as support to improve knowledge about vaccination and immunization coverage.

Keywords: Attitudes, Behavior, Italy, Knowledge, Parents, Vaccination, Varicella

\section{Background}

It is well known that varicella is one of the most common and highly contagious viral diseases in childhood and it can be fatal especially in neonates due to its serious complications [1]. The adoption of childhood prophylactic vaccine against varicella-zoster virus has been shown to be safe and efficacious in reducing the incidence and morbidity associated [2].

In Italy the vaccine is licensed since 1994 [3] and the routine immunization has been introduced in the National Vaccination Plan 2012-2014 beginning with

\footnotetext{
* Correspondence: italof.angelillo@unina2.it

Department of Experimental Medicine, Second University of Naples, Via Luciano Armanni, 5, 80138 Naples, Italy
}

the 2014 birth cohort with the achievement and maintenance of vaccine coverage $\geq 95 \%$ for one dose within 2 years of age, and two doses in children aged 5-6 years of age [4]. However, the immunization is provided free of charge only in few geographic areas mainly because the National Health Service has been decentralized from the 2001 and the 20 regions are responsible for delivering public health and health-care services and, therefore, they may adopt different policies. In 2014, Campania Region had adopted a free of charge universal varicella vaccination programme targeting children and susceptible adolescents, according to the National Vaccination Plan [5].

However, the infant and childhood vaccination coverage unfortunately appear to be inadequate. Parents have 
an important and critical role in order to protect their children from acquiring and transmitting varicella by improving the coverage since their lack of knowledge and lower perception about the benefit of the vaccination could influence their choice for not vaccinating their son or daughter. Therefore, it is important to discover the perceptions linked to vaccination practices in order to improve parental awareness and coverage.

Different studies have shown that children's parents could underestimate the incidence and severity of the varicella infection and that increasing awareness and knowledge about the disease and the vaccination are a key-factor to improve vaccine coverage [6-11]. So far, to the best that we could ascertain, little is known about this topic among parents of children in Italy. Therefore, the present investigation examined the level of knowledge of varicella infection and its vaccination, and the attitudes and behavior regarding the vaccination and to get insight into their determinants among parents of children in Italy.

\section{Methods}

\section{Setting and participants}

From May to June 2015, a cross-sectional survey was conducted in the city of Naples (Italy). Four kindergartens and primary public schools were randomly selected.

The head teacher of the selected kindergartens and schools was contacted by the research team and solicited for participation. After the approval, in each kindergarten and school, 8 classes were selected randomly and the sample was of 675 parents of children from 4 years of age until reaching 7 years of age. The minimum sample size required for the study was determined based on the assumptions of a prevalence of positive attitude regarding varicella immunization among parents of $50 \%$, a $95 \%$ confidence interval, and a desired degree of accuracy of 0.05 . To compensate the non-response rate, $40 \%$ of the determined sample was added up on the calculated sample size and the final sample size was 640 .

\section{Procedure}

The children selected received an envelope randomly addressed to either the mother or the father. The envelope included a letter with information on the study objectives, a two-page anonymous and confidential self-administered questionnaire, and a self-addressed envelope for returning the questionnaire to the research team. In the letter and at the beginning of the questionnaire, participants were assured of their privacy, that the survey was anonymous, and that the questionnaire responses were not linked with the participants' identification. The letter also indicated that they received the questionnaire because their child was randomly selected in the kindergarten or in the school and they were given instructions to return the completed questionnaire to the kindergarten or the school within three days. If the questionnaire was not returned in the prescribed time, the research team made a reminder phone calls to the head teacher. No incentives were offered for completion of the survey. Respondents were never contacted directly by the research team.

\section{Questionnaire}

A self-administered structured questionnaire was developed and pilot-tested among a convenience sample of 40 parents, who were interviewed to gain feedback on the overall acceptability of the questionnaire in terms of length, clarity, and question formats. The internal reliability was estimated through Cronbach's $\alpha$ [12]. The questionnaire including 29 questions was structured in five sections [Additional file 1]. The first section involved questions regarding sociodemographic variables of the respondent (gender, age, marital status, degree of education, occupation, number of children) and of the selected child (age, birth order). The questions in the second section were about the knowledge about varicella, transmission route of the infection, and vaccination. The third section investigated the attitudes towards varicella and the vaccination. In the fourth section participants were asked to report whether they had vaccinated for varicella the selected child or any other child of at least 2 years old. Participants whose selected child was not vaccinated were asked whether they would or would not vaccinate their selected child or the other children in the future and subsequently giving reasons why or why not to vaccinate. Potential barriers, comprised a lack of information, concerns about efficacy, side effects, disapproval by the physician, and time constraints. Lastly, the fifth part assessed the awareness of the information about varicella and vaccination and the source of their information. Each part consisted of questions on a 10-grade Likert type scale ranging from 1 (Not worried, Not dangerous, Not useful) to 10 (Much worried, Very dangerous, Very useful), multiple-choice, and open-ended.

The Ethical Committee of the Second University of Naples approved the survey instrument and study protocol.

\section{Statistical analysis}

Initially, to explore the association between the dependent variable and the independent variables, one at a time, a univariate analysis was performed. Chi-square test was used for comparisons of categorical variables, Student's $t$-test was applied for continuous variables. Subsequently, if the outcomes of interest were associated with each independent variable with a $p \leq 0.25$ in the univariate analysis, the variable was included in the multivariable linear and logistic regression models. The outcome variables were the following: knowledge regarding the availability of the varicella vaccine and the number of doses required (Model 1); 
positive attitude towards the utility of varicella vaccination (Model 2); and selected child's vaccination uptake against varicella (Model 3). Independent variables tested at the univariate analysis for the inclusion into the models were the following: birth order and age of the selected child, age, marital status, educational level, number of children, knowledge about the disease (etiology, route of transmission), knowledge about the varicella vaccination (availability, dosage), perceived danger of disease, perceived utility of the varicella vaccination, information on the disease from a health care provider, information on the vaccination from a health care provider, need of additional information about varicella vaccination, history of varicella among at least one child, and vaccination of the selected child. Results from the stepwise linear regression models were presented as $\beta$ coefficients and standard errors. The results of the logistic regression models were presented as odds ratios (ORs) with 95\% confidence intervals (95\% CIs). The $p$ value for variables entering in the logistic regression models was 0.2 and the $p$ value to remain in the model was 0.4 . All reported $p$ values were based on two-tailed tests and were considered statistically significant at $p=0.05$ or less. All data were analyzed using Stata version 10.1 statistical software [13].

\section{Results}

Internal consistency reliability assessed using Cronbach's $\alpha$ was 0.62 . Of the 675 questionnaire distributed, a total of 414 parents participated for a response rate of $61.3 \%$. As shown in Table 1, more than two-thirds were female, the average age was 40.4 years, the majority was married, for $49 \%$ of the respondents the selected child was firstborn, the median number of children was two, one-third was small employers and own account workers, and approximately half attained a university degree.

The vast majority of the parents answered correctly the statement that varicella is an infectious disease (91.9\%) and that the transmission is mainly person to person by airborne respiratory droplets, direct contact with vesicle fluid of chickenpox cases and of patients with herpes zoster (68.9\%). More than three-quarter $(82.6 \%)$ knew that a vaccine is currently available, however, only $34.2 \%$ of the sample know the number of doses. Overall, participants were poor knowledgeable since $26.6 \%$ answered correctly that the vaccine was available and the number of doses required. A multivariable logistic regression analysis was conducted to establish a model with more than one variable that can predict the knowledge about the varicella vaccination. The analysis suggests that parents with a level of education not higher than middle school (OR $=0.41 ; 95 \%$ CI $0.17-0.99)$ were less likely to be knowledgeable in comparison with those who had a university degree, whereas those who had received information on the vaccination from a health care provider $(\mathrm{OR}=2.35 ; 95 \% \mathrm{CI} 1.14-4.85)$ and who had
Table 1 Self-reported characteristics of the participants in the study

\begin{tabular}{llc}
\hline & $\mathrm{N}$ & $\%$ \\
\hline Gender (414) & & \\
Male & 113 & 27.3 \\
Female & 301 & 72.7 \\
Age (years) (408) & $40.4 \pm 6$ & $(22-58)^{\mathrm{a}}$ \\
$18-30$ & 25 & 6.1 \\
$31-35$ & 57 & 14 \\
$36-40$ & 112 & 27.4 \\
$41-45$ & 137 & 33.6 \\
$>45$ & 77 & 18.9 \\
Marital status (411) & & \\
Married & 334 & 81.3 \\
Other & 77 & 18.7
\end{tabular}

Education level (411)

No formal education, elementary or middle school $68 \quad 16.5$

High school

$147 \quad 35.8$

College degree or higher

$196 \quad 47.7$

Socioeconomic status (395)

Low

$164 \quad 41.5$

Middle

$131 \quad 33.2$

High

$100 \quad 25.3$

Number of children (414)

1

2

$\geq 3$

$88 \quad 21.3$

$227 \quad 54.8$

$99 \quad 23.9$

Number of children by age (years) (414)

4

5

6

7

$50 \quad 12.1$

$68 \quad 16.4$

$151 \quad 36.5$

$145 \quad 35$

Birth order of the selected children (414)

$\begin{array}{lll}\text { First } & 203 & 49 \\ \text { Second } & 149 & 36 \\ \text { Third } & 48 & 11.6 \\ \text { Fourth and more } & 14 & 3.4\end{array}$

Varicella vaccination according to the age (years) of the selected children $(156)^{\mathrm{b}}$

$\begin{array}{lll}4-5 & 45 & 28.8\end{array}$

$6-7$

$111 \quad 71.2$

In brackets there is the number of parents reporting the information Number for each item may not add up to total number of study population due to missing value

${ }^{a}$ Mean \pm standard deviation (range)

${ }^{\mathrm{b}}$ Only for the selected children who had been vaccinated 
vaccinated their child against varicella $(\mathrm{OR}=4.94 ; 95 \% \mathrm{CI}$ 2.84-8.58) were more knowledgeable (Model 1 in Table 2).

The results regarding attitudes and beliefs indicated that only $2.2 \%$ of the parents believed that varicella could cause serious health problems with an overall mean value of 3.9 on a 1 to 10 scale, whereas the overall perceived utility towards vaccination as a way to protect their child was low, with a mean value of 5.7. Multiple linear regression analysis showed that parents with a

Table 2 Multivariate analysis indicating associations between several variables and the outcomes regarding vaccination against varicella

\begin{tabular}{|c|c|c|c|c|}
\hline Variable & OR & SE & $95 \% \mathrm{Cl}$ & $p$ \\
\hline \multicolumn{5}{|c|}{ Model 1: Knowledge regarding the availability of the vaccine and the number of doses required } \\
\hline \multicolumn{5}{|c|}{ Log likelihood $=-186.82, x^{2}=81.42(8 \mathrm{df}), p<0.0001$} \\
\hline Vaccination of the selected child & 4.94 & 1.39 & $2.84-8.58$ & $<0.001$ \\
\hline Information on the vaccination from a health care provider & 2.35 & 0.87 & $1.14-4.85$ & 0.02 \\
\hline \multicolumn{5}{|l|}{ Educational level } \\
\hline College degree or higher & $1^{\text {a }}$ & & & \\
\hline High school & 0.59 & 0.17 & $0.33-1.06$ & 0.077 \\
\hline No formal education/elementary school/middle school & 0.41 & 0.18 & $0.17-0.99$ & 0.047 \\
\hline Age & 1.05 & 0.03 & $0.99-1.10$ & 0.073 \\
\hline \multicolumn{5}{|l|}{ Number of children } \\
\hline One & $1^{\mathrm{a}}$ & & & \\
\hline Three or more & 0.59 & 0.20 & $0.30-1.16$ & 0.128 \\
\hline Knowledge about disease (etiology and transmission) & 1.49 & 0.40 & $0.88-2.52$ & 0.133 \\
\hline History of varicella among at least one child & 0.71 & 0.20 & $0.41-1.24$ & 0.237 \\
\hline Variable & Coeff. & SE & $t$ & $p$ \\
\hline \multicolumn{5}{|c|}{ Model 2: Positive attitude towards the utility of varicella vaccination } \\
\hline \multicolumn{5}{|l|}{$F(6,380)=59.20, R^{2}=0.48 \%$, adjusted $R^{2}=0.47 \%, p<0.0001$} \\
\hline Perceived danger of the disease & 0.43 & 0.05 & 8.54 & $<0.001$ \\
\hline Vaccination of the selected child & 3.45 & 0.27 & 12.55 & $<0.001$ \\
\hline \multicolumn{5}{|l|}{ Educational level } \\
\hline College degree or higher & $1^{\mathrm{a}}$ & & & \\
\hline High school & 0.49 & 0.27 & 1.80 & 0.073 \\
\hline No formal education/elementary/middle school & 1.43 & 0.37 & 3.91 & $<0.001$ \\
\hline Information on the vaccination from a health care provider & 0.71 & 0.30 & 2.39 & 0.018 \\
\hline History of varicella among at least one child & -0.50 & 0.26 & -1.91 & 0.057 \\
\hline Variable & OR & SE & $95 \% \mathrm{Cl}$ & $p$ \\
\hline \multicolumn{5}{|l|}{ Model 3: Selected child's vaccination uptake against varicella } \\
\hline \multicolumn{5}{|l|}{ Log likelihood $=-149.72, x^{2}=215.36(8 \mathrm{df}), p<0.0001$} \\
\hline Perceived utility of varicella vaccination & 1.66 & 0.10 & $1.48-1.86$ & $<0.001$ \\
\hline Knowledge about the varicella vaccination & 4.70 & 1.59 & $2.42-9.12$ & $<0.001$ \\
\hline History of varicella among at least one child & 0.40 & 0.12 & $0.23-0.72$ & 0.002 \\
\hline Perceived danger of the disease & 0.85 & 0.05 & $0.75-0.96$ & 0.01 \\
\hline Marital status & 0.54 & 0.19 & $0.27-1.07$ & 0.078 \\
\hline Information on the vaccination from a health care provider & 1.95 & 0.84 & $0.83-4.56$ & 0.125 \\
\hline Age & 0.97 & 0.02 & $0.92-1.01$ & 0.180 \\
\hline Information on the disease from a health care provider & 0.71 & 0.28 & $0.33-1.53$ & 0.384 \\
\hline
\end{tabular}


level of education not higher than middle school, those who reported that they had vaccinated their child against varicella, those who considered the varicella to be a dangerous disease, and those who had received information on the vaccination from a health care provider were more likely to have a positive attitude towards the utility of varicella vaccination (Model 2 in Table 2).

A history of varicella was reported in 163 of the selected children (39.6\%). More than one-third of the respondents (38.4\%) stated that they had vaccination their child and almost two-thirds of them (60.5\%) were actually encouraged by their health care provider to vaccinate. The results of the multivariate logistic regression analysis examining the variables associated with selected children's vaccination uptake against varicella showed that four variables were independently predictive of the vaccination. The strongest predictor was the personal knowledge about the varicella vaccination, respondents with this knowledge had an almost 5 times greater odds of vaccination than nonknowledgeable respondents (95\% CI 2.42-9.12). Parents who had not a history of varicella among their children $(\mathrm{OR}=0.4 ; 95 \% \mathrm{CI} 0.23-0.72)$, those who believed that the disease was not dangerous ( $\mathrm{OR}=0.85$; 95\% CI 0.75-0.96), and those who had the personal beliefs about the utility of the vaccination $(\mathrm{OR}=1.66$; $95 \% \mathrm{CI} 1.48-1.86)$ were more likely to have vaccinated their child against varicella (Model 3 in Table 2). Of the parents who had not vaccinated against varicella their child, only $20.8 \%$ stated that they would be willing to vaccinate their child and the main reasons for vaccine acceptance were that it was useful (39.2\%) and that the disease can give complications (23.5\%), whereas the most reported reasons for nonacceptance of the vaccine were that their child had already get the varicella $(44.2 \%)$, that the varicella was not dangerous (39.2\%), and that the health care provider did not recommend the vaccination (23.6\%).

Almost all participants, reported that they had ever heard of the varicella (99.3\%) before study participation, and the most reported sources for advice were family or friends (80.5\%), $74.2 \%$ a health care provider, and $17.5 \%$ through TV, radio, magazine or newspaper articles. For those who answered that they had heard of the vaccine (92\%), 83.3\% indicated a health care provider, $52.3 \%$ family or friends, and $13.1 \% \mathrm{TV}$, radio, magazine or newspaper articles. Onethird of the parents surveyed (35.2\%), whether they would be willing to vaccinate their child or not, desired more information regarding varicella vaccination.

\section{Discussion}

The results of the present study have improved the understanding of the parental knowledge, attitudes, and practices toward varicella infection and vaccination for children in Italy.
Regarding knowledge related to varicella and its vaccine, sampled parents answered correctly that it is an infectious disease and about the way of transmission, but knowledge on the vaccine was seriously poor since only one fourth knew that one was available and correctly indicated the number of doses. This finding is of concern because the government has included varicella in its immunization program $[4,14,15]$. These results are in accordance to similar studies conducted in USA [16] and Canada [17], with respectively 73.3 and 68\% who were aware about the availability of the vaccine. Moreover, high knowledge was found in Germany [18], where the 95, 94.2, and $95.5 \%$ knew the existence of the vaccine. Lastly in UK [19], only $26 \%$ of parents had heard about the availability of the vaccination and in the Hawaii [20] 32\% said they had no knowledge about the vaccine. The finding that an adequate level of knowledge about the varicella vaccination was a significant predicting factor for vaccination acceptance supports the importance of the knowledge. This indicates that an educational campaign should also cover beliefs and behaviors associated with the acceptance of vaccination.

An important result from this study is that, despite the vaccine in the selected sample was not provided free of charge, $38.4 \%$ of the respondents stated that they had vaccinated against varicella their child. Similar results have been observed in Israel with an immunization rate of $35.2 \%$ [21] and 34.1\% [22], whereas higher values have been found in Taiwan with 69\% [23], in Greece with $87.5 \%$ [24] and $61.1 \%$ [25], and in USA with $68 \%$ [26]. Whereas, lower values have been found in India (27.1\%) [27], in Canada (21-28\%) [28], and in Poland (4.2\%) [29]. The low value regarding the vaccination in the present study is a possible explanation of the low overall perceived utility towards varicella vaccination as a way to protect their child, with a mean value of 5.7 in a 10 point scale, and of only $20.8 \%$ stated that they would be willing to vaccinate their child. About the perceived utility towards varicella vaccination, a higher value was found in Turkey with a mean value of 3.68 in a 5 -point scale [30] and in USA with 4.4 in a 6-point scale [31]. In the already mentioned survey conducted in Germany, $83-94 \%$ of parents who vaccinated their children believed that varicella vaccine was useful, while only $20-30 \%$ of those who did not vaccinate their children thought that the immunization was useful [18].

The findings from the multivariable analysis showed several interesting associations. The contribution of the socio-demographic variables to the outcomes of interest indicated that only respondent's educational level remained in the multivariate analyses predicting two outcomes of interest. Among the respondents with a university degree, the level of knowledge regarding the availability of varicella 
vaccine and the number of doses was significantly higher compared to those with a lower level of education. Previous studies showed that those with higher education were more likely to know the vaccination $[6,7,10,22]$. This may be explained by the fact that parents with higher education background may have more access to health information and thus achieve higher knowledge and this is also sustained by the positive association between knowledge and information acquired by health care providers. The importance of the poor knowledge regarding the vaccination was also highlighted by the fact that being well-informed was the most significant predictor of having vaccinated a child. Moreover, the parents' educational level has also a significant impact on the attitude towards the utility of varicella vaccination with parents with a level of education not higher than middle school were more likely to have a positive attitude [32].

A remarkable finding was that the health care providers were one of the most frequently consulted information sources on the vaccination by the respondents, followed by mass media, and friends or family. As expected, information delivered from a health care provider is effective, because these respondents had a significantly greater level of knowledge about the vaccine compared with those who had received advice from other sources. The result that physician recommendation is a key predictor of knowledge about vaccination underline the fact that they are in an unique position in conveying and acquiring knowledge and in educating and recommending the vaccine. The findings further support that they are an important and trustworthy source of information for parents regarding childhood vaccinations. Thus, educating parents regarding the varicella and the vaccination to acquire information from health care providers is paramount in order to encourage such population to vaccinate their child. Other research has demonstrated the importance of the physician in determining parent's knowledge of vaccination for themselves or their child and of preventive health behaviors $[9,11,16-18,20,21,32-43]$. However, it should be noted that health care providers had no effect on the decision of the parents to vaccinate their child although those who had received information on the vaccination from this source were likely to have a positive attitude towards the utility of the vaccine. It is therefore essential that health care providers should be aware of their role in communicating with parents regarding varicella vaccine and they must take advantage of every encounter to inform parents in line with the advice of health authorities also because one of the most important reasons for declining vaccination was that they had not recommended it.

As in all similar epidemiological research, certain limitations in the study design should be considered. First, the data are cross-sectional and although we were able to identify associations between the outcomes of interest and certain study factors, caution should be taken when interpreting the findings owing to the nature of the study method employed that prevents us from making any statements regarding temporality and causal relationships. Second, due to the self-administered nature of the questionnaires, data on the vaccination status was not confirmed by other data sources and therefore recall and reporting bias may have been introduced. We are however confident that reliable estimates have been collected given that many participants indicated that their daughter/son did not receive the vaccine, so overestimation of uptake is unlikely, and that a child could only receive the vaccine with consent of an adult caregiver, so it is very likely that one parent accompanied them and thus knows the number of doses received. Third, potential for socially desirable answers may lead to reporting bias with a tendency to agree with statements when in doubt or to over-reporting acceptability of the vaccination. Because of the cross-sectional nature of the study, it is unclear whether parents with positive attitudes toward varicella vaccination will actually vaccinate their children in the future, although a self-administered anonymous questionnaire should have allowed parents to respond more accurately to the questions.

\section{Conclusions}

To conclude, the current investigation suggests a substantial need for educational campaigns to disseminate knowledge about varicella among parents and repeated exposure to information from health care providers about varicella and vaccination may result in high rates of vaccination.

\section{Additional file}

Additional file 1: Questionnaire. (DOCX $49 \mathrm{~kb}$ )

Abbreviations

Cl: Confidence interval; OR: Odds ratio; SE: Standard error

\section{Acknowledgements}

The authors wish to express their sincere appreciation to all authorities of the schools for giving permission to collect the data and to all the study participants for generously contributing their time.

\section{Funding}

The authors have no support or funding to report.

\section{Availability of data and materials}

Data and supporting materials associated with this study will be provided upon request by the corresponding author.

\section{Authors' contributions}

LV participated in the design of the study, was responsible for the data collection, contributed to the data analysis and interpretation; GS participated in the design of the study, contributed to the data collection, contributed to the data analysis 
and interpretation; IFA, the principal investigator, designed the study, was responsible for the statistical analysis and interpretation, and wrote the article. All authors have read and approved the final version of the manuscript.

\section{Competing interests}

The authors declare that they have no competing interests.

\section{Consent for publication}

Not applicable.

\section{Ethics approval and consent to participate}

The Ethical Committee of the Second University of Naples approved the survey instrument and study protocol.

All participants provided written informed consent at the beginning of the survey prior to answering any question by reading the consent form.

Received: 5 June 2016 Accepted: 7 February 2017

Published online: 27 February 2017

\section{References}

1. WHO. Varicella and herpes zoster vaccines: WHO position paper, June 2014. 2014. http://www.who.int/wer/2014/wer8925.pdf?ua=1. Accessed 30 May 2016.

2. ECDC. ECDC Guidance - Varicella vaccination in the European Union. 2015. http://ecdc.europa.eu/en/publications/Publications/Varicella-Guidance-2015. pdf. Accessed 30 May 2016.

3. Ministero della Salute. Decreto del Direttore Generale del Servizio Farmaceutico, 31/10/1994, n. A/1226 /1994. 1994. Autorizzazione all'immissione in commercio di Varilrix (AIC) n. 028427019.

4. Ministero della Salute. Piano Nazionale Prevenzione Vaccinale (PNPV) 2012 2014. Intesa Stato-Regioni, 22/2/2012. http://www.salute.gov.it/imgs/c_17_ pubblicazioni_1721_allegato.pdf. Accessed 30 May 2016.

5. Regione Campania. Bollettino Ufficiale della Regione Campania. n.7 del 2/2/ 2015. Delibera della Giunta Regionale n. 2 del 9/1/2015. http://burc.regione. campania.it/eBurcWeb/directServlet?DOCUMENT_ID=75420\&ATTACH_ID= 107180. Accessed 24 Nov 2016.

6. Angelillo IF, Ricciardi G, Rossi P, Pantisano P, Langiano E, Pavia M. Mothers and vaccination: knowledge, attitudes, and behaviour in Italy. Bull World Health Organ. 1999;77(3):224-9.

7. Impicciatore P, Bosetti C, Schiavio S, Pandolfini C, Bonati M. Mothers as active partners in the prevention of childhood diseases maternal factors related to immunization status of preschool children in Italy. Prev Med. 2000;31(1):49-55.

8. Pandolfi E, Graziani MC, leraci R, Cavagni G, Tozzi AE. A comparison of populations vaccinated in a public service and in a private hospital setting in the same area. BMC Public Health. 2008:8:278.

9. Coniglio MA, Platania M, Privitera D, Giammanco G, Pignato S. Parent's attitudes and behaviours towards recommended vaccinations in Sicily. Italy BMC Public Health. 2011;11:305

10. Al-lela OQ, Bahari MB, Salih MR, Al-Abbassi MG, Elkalmi RM, Jamshed SQ. Factors underlying inadequate parents' awareness regarding pediatrics immunization: findings of cross-sectional study in Mosul- Iraq. BMC Pediatr. 2014;14:29.

11. MacDonald SE, Schopflocher DP, Vaudry W. Parental concern about vaccine safety in Canadian children partially immunized at age 2: a multivariable model including system level factors. Hum Vaccin Immunother. 2014;10(9):2603-11.

12. Cronbach L. Coefficient alpha and the internal structure of tests. Psychometrika. 1951;16:297-334.

13. Stata Corporation. Stata reference manual, release 10.1, College Station, Tex, USA. 2007.

14. Ministero della Salute. Piano Nazionale Vaccini 2005-2007. Conferenza Stato Regioni. Gazzetta Ufficiale n. 86 14/4/2005. Supplemento ordinario n. 63. http://www.salute.gov.it/imgs/C_17_pubblicazioni_543_allegato.pdf. Accessed 30 May 2016.

15. Bechini A, Boccalini S, Baldo V, Cocchio S, Castiglia P, Gallo T, et al. Impact of universal vaccination against varicella in Italy. Hum Vaccin Immunother 2015;11(1):63-71.

16. Freeman VA, Feed GL. Parental knowledge, attitudes, and demand regarding a vaccine to prevent varicella. Am J Prev Med. 1999;17(2): 153-5.
17. De Courval FP, De Serres G, Duval B. Varicella vaccine: factors influencing uptake. Can J Public Health. 2003;94(4):268-71.

18. Streng A, Seeger K, Grote V, Liese JG. Varicella vaccination coverage in Bavaria (Germany) after general vaccine recommendation in 2004. Vaccine. 2010;28(35):5738-45

19. Lee E, Turner J, Bate J. Parental opinions on childhood varicella and the varicella vaccine: a UK multicenter qualitative interview study. Arch Dis Child. 2011;96(9):901.

20. Niederhauser VP, Baruffi G, Heck R. Parental decision-making for the varicella vaccine. J Pediatr Health Care. 2001;15(5):236-43.

21. Miron E, Abu-Foul N, Rishpon S. Factors affecting Varicella vaccine uptake among children 1-17 years old in the Haifa District in 2007. Hum Vaccin. 2010;6(10):849-53

22. Adler A, Herring E, Babilsky H, Gazala E, Cohen A, Levy I. Parent-dependent barriers to varicella immunization in Israel: the importance of adequate information. Acta Paediatr. 2007;96(3):428-31.

23. Tam WW, Chan J, Lo KK, Lee A, Chan PK, Chan D, et al. Parental attitudes and factors associated with varicella vaccination in preschool and schoolchildren in Hong Kong: a cross-sectional study. Medicine (Baltimore). 2015;94(36):e1519.

24. Vassiliki P, loanna K, Artemis V, Eleni K, Aglaia Z, Attilakos A, et al. Determinants of vaccination coverage and adherence to the Greek national immunization program among infants aged 2-24 months at the beginning of the economic crisis (2009-2011). BMC Public Health. 2014;14:1192.

25. Pavloupoulou ID, Michail KA, Samoli E, Tsiftis G, Tsoumakas K. Immunization coverage and predictive factors for complete and age-appropriate vaccination among preschoolers in Athens, Greece; a cross sectional study. BMC Public Health. 2013;13:908.

26. Keane MT, Walter MV, Patel BI, Moorthy S, Stevens RB, Bradley KM, et al. Confidence in vaccination: a parent model. Vaccine. 2005;23(19):2486-93.

27. Manthiram K, Blood EA, Kuppuswamy V, Martins Y, Narayan A, Burmeister K, et al. Predictors of optional immunization uptake in an urban south Indian population. Vaccine. 2014;32(27):3417-23.

28. Gustafson R, Skowronski DM. Disparities in varicella vaccine coverage in the absence of public funding. Vaccine. 2005;23(27):3519-25.

29. Ganczak M, Dmytrzyk- Daniłów G, Karakiewicz B, Korzén M, Szych Z. Determinants influencing self-paid vaccination coverage, in $0-5$ years old Polish children. Vaccine. 2013;31(48):5687-92.

30. Gundogdu Z, Gundogdu O. Parental attitudes and varicella vaccine in Kocaeli, Turkey. Prev Med. 2011;52(3-4):278-80.

31. Taylor JA, Newman RD. Parental attitudes toward varicella vaccination. The Puget Sound Pediatric Research Network. Arch Pediatr Adolesc Med. 2000; 154(3):302-6.

32. Boulianne NA, Duval B, Serres GD. Opinions of Quebec parents and vaccinators on the usefulness of chickenpox vaccine. Can J Infect Dis. 2001; 12(3):153-6.

33. Grabowsky M, Orenstein WA, Marcuse EK. The critical role of provider practices in undervaccination. Pediatrics. 1996;97(5):735-7.

34. Freed GL, Clark SJ, Hibbs BF, Santoli JM. Parental vaccine safety concerns. The experiences of pediatricians and family physicians. Am J Prev Med. 2004;26(1):11-4.

35. Gust DA, Kennedy A, Shui I, Smith PJ, Nowak G, Pickering LK. Parent attitudes toward immunizations and healthcare providers the role of information. Am J Prev Med. 2005;29(2):105-12.

36. Heininger U. An internet-based survey on parental attitudes towards immunization. Vaccine. 2006;24(37-39):6351-5.

37. Smith PJ, Kennedy AM, Wooten K, Gust DA, Pickering LK. Association between health care providers' influence on parents who have concerns about vaccine safety and vaccination coverage. Pediatrics. 2006;118(5): e1287-92.

38. Liao SL, Huang T, Huang YC, Jiang DD. Survey of the status of self-paid varicella vaccination among children one to six years of age in Taiwan. J Microbiol Immunol Infect. 2007;40(2):112-5.

39. Gust DA, Darling N, Kennedy A. Parents with doubts about vaccine: which vaccines and reasons why. Pediatrics. 2008;122(4):718-25.

40. Salmon DA, Pan WK, Omer SB, Navar AM, Orenstein W, Marcuse EK, et al. Vaccine knowledge and practices of primary care providers of exempt vs. vaccinated children. Hum Vaccin. 2008:4(4):286-91.

41. Wu AC, Wisler-Sher DJ, Griswold K, Colson E, Shapiro ED, Holmboe ES, et al. Postpartum mothers' attitudes, knowledge, and trust regarding vaccination. Matern Child Health J. 2008;12(6):766-73. 
42. Allaert FA, Blanc A, Megard Y, Bertand Y. Parents' attitudes towards varicella vaccination acceptance in France and Germany: effect of vaccine recommendation and reimbursement (a survey). J Public Health. 2009:17:71-6.

43. Mergler MJ, Omer SB, Pan WK, Navar-Boggan AM, Orenstein W, Marcuse EK, et al. Association of vaccine-related attitudes and beliefs between parents and health care providers. Vaccine. 2013;31(41):4591-5.

Submit your next manuscript to BioMed Central and we will help you at every step:

- We accept pre-submission inquiries

- Our selector tool helps you to find the most relevant journal

- We provide round the clock customer support

- Convenient online submission

- Thorough peer review

- Inclusion in PubMed and all major indexing services

- Maximum visibility for your research

Submit your manuscript at www.biomedcentral.com/submit 